\title{
Routine referrals: A possible solution for transplantation shortages
}

\author{
M Slabbert, ${ }^{1}$ BA (Hons) HED, B Proc, LLB, LLD; B Venter, ${ }^{2}$ LLB, LLM \\ 1 Department of Jurisprudence, School of Law, University of South Africa, Pretoria \\ ${ }^{2}$ Faculty of Law, Pearson Institute of Higher Education, Midrand, South Africa
}

Corresponding author: B Venter (bonnie.venter@pearson.com)

\begin{abstract}
Transplantation is the only therapeutic option for terminal organ failure. The principle that donation should be a routine component of endof-life care is recognised in many countries, but only $38 \%$ of them have official deceased-donor programmes, and South Africa (SA) does not have one. Scrutinising the policies in countries such as Spain, the UK and the USA (Pennsylvania), where official referral programmes exist, could help to determine which option will be best suited to SA. It is concluded that the best basic step to start with in SA would be if the Department of Health could implement a routine-referral policy document, compelling physicians to refer every death to be evaluated for the possibility of organ retrieval.
\end{abstract}

SAfr J Bioethics Law 2017;10(1):15-19. DOI:10.7196/SAJBL.2017.v10i1.498

There is a dire need for transplantable human organs worldwide, and South Africa (SA) is no exception. Organ transplantation is a unique operation, as a patient can only become the recipient of a transplant because another human has donated the organ, either in life or after death. There are not nearly enough available transplantable organs to supply the demand; therefore, all countries and regions of the world are encouraged to work towards self-sufficiency, with as much emphasis on disease reduction as on increasing donation. ${ }^{[1]}$ According to the Declaration of Istanbul on Organ Trafficking and Transplant Tourism, 'legislation should be developed and implemented by each country or jurisdiction to govern the recovery of organs from deceased and living donors and the practice of transplantation, consistent with international standards. Policies and procedures should be developed and implemented to maximise the number of organs available for transplantation, consistent with these principles.'

While the demand for transplants in SA is steadily increasing, the supply of deceased donors has remained mainly stagnant or it has declined. There are currently 1349 patients waiting for a solid organ transplant, while only 364 transplants of solid organs were performed in 2015.[2] Of these 364 transplants, 215 organs came from deceased donors. This number is very low if a population of 55 million is taken into account. According to Statistics $\mathrm{SA}_{1}^{\left[{ }^{[3]}\right.} 458933$ deaths were recorded in 2013. Not all deaths will lead to potential organ usage, but the numbers could be an indication of possibilities, as 5698 people died owing to motor vehicle accidents alone. A total of 21937 of the recorded deaths were people between the ages of 15 and 24 , the biggest pool of organ donors. It is also interesting to note that 23393 people died in 2013 because of renal failure. ${ }^{[3]}$ It therefore seems worthwhile to investigate the potential to increase the deceased-donor rate in order to try and fulfil the demand.

Transplantation is the only therapeutic option for terminal organ failure. The principle that donation should be a routine component of end-of-life care is recognised in many countries, but only $38 \%$ of them have official deceased-donor programmes, of which SA is not one. ${ }^{[4]}$ By scrutinising the policies in countries where an official referral programme exists, it could be determined which option will be best suited for SA. When evaluating deceased-donor programmes elsewhere, two ethical principles underpinning the procurement of organs for transplantation should constantly be kept in mind. These principles are the deceased-donor rule and informed consent. The deceased-donor rule states that vital organs can only be retrieved after an individual has died. The rule also emphasises that retrieval of donated organs must not cause the donor's death. SA adheres to this principle. According to the World Health Organization (WHO), explicit consent is defined as a system in which cells, tissue or organs may be removed from a deceased person if the person has 'expressly consented to such removal during his or her lifetime.[5] In this regard, SA disregards the express will of the donor as indicated by a donor card (or any other means), as the family of the deceased are always routinely asked in practice for permission to remove possible transplantable organs. This happens because having a donor card or being registered with the Organ Donor Foundation is not legally enforceable, as the National Health Act 61 of 2003 (NHA) requires a signed document that has been attested by two competent witnesses. Registering as an organ donor does not require any attestation at this point. The donor's explicitly stated wish to donate can therefore be overruled by family members, who have the right to veto a potential donor's wish.

Organ donations in SA are regulated by the NHA and the regulations regarding the general control of human bodies, tissue, blood, blood products and gametes. In this article the process of organ procurement in SA is briefly explained, as well as the determination of brain death. Furthermore, the issue of who may give consent is highlighted. The focus is on deceased donors only.

There are three deceased organ donation pathways in practice. The first two are more relevant to intensive care, while the third is more commonly facilitated from an emergency department: 
- donation after brain death (DBD) - neurological criteria

- donation after circulatory death (DCD) - cardiorespiratory criteria

- uncontrolled (DCD) - an unexpected cardiac arrest and death is confirmed using cardiorespiratory criteria after resuscitation efforts have been unsuccessful.

To avoid a perceived conflict of interest, it is imperative that there is a disconnection between decisions about treatment withdrawal and subsequent discussions about the potential for organ donation. ${ }^{\left[{ }^{[6]}\right.}$ On average, 3.8 organs are transplanted successfully after retrieval from brain-dead patients compared with 2.7 organs from DCD donors. In SA it is mainly brain-dead people who are used as organ donors. In conclusion, it is argued that all end-of-life cases in SA should, by means of routine referral, be recommended for potential organ donation.

\section{Deceased-donor organ retrieval in SA}

The NHA defines 'death' as brain death. The Act itself does not indicate how brain death should be determined. In the regulations to the Act it is stated that the death of a person shall be established by at least two medical practitioners, one of whom shall have been practising as a medical practitioner for at least 5 years, and none of the medical practitioners should be part of the team performing the transplant. The tests done by the physicians to determine whether the brain stem is dead are of a neurological nature only. Once a person is declared brain dead, the option of organ donation may then be addressed. This is not common practice in SA; it happens on an ad hoc basis depending on workload, the availability of resources and time and whether the hospital staff have knowledge of or are in favour of organ donation. In other words, not all brain-dead patients are routinely referred to a transplant co-ordinator, who would be a direct contact point between the potential organ donor and the potential organ recipient on a waiting list. In many cases the ventilators are switched off, and healthy organs that could have been transplanted go to waste.

Section 62 of the NHA concerns the donation of human bodies and tissue, which includes organs of deceased persons. The section states that a person who is competent to make a will ( 16 years old or more) may donate his or her organs in a will or in a document signed by him or her and at least two competent witnesses. The person may also, while alive, state orally in the presence of two competent witnesses (14 years or older) that his or her organs may be used for transplantation after death. SA therefore follows a system known as 'opting in', meaning an individual indicates a wish to be an altruistic donor after death, while still alive. Section 62(2) further states that if the deceased has not expressed a decision on organ donation before death, the spouse, partner, major child, parent, guardian, major brother or sister, in this specific order, might be asked for a possible donation. This is the usual practice in all SA hospitals. The family is asked for consent to remove usable organs for transplantation into a patient irrespective of the deceased not having a donor card or any other indication that he or she is a donor. If none of the above is possible, the Director General of the Department of Health may donate any specific tissue after all steps have been taken to locate family members.

The regulations to the Act state in section 8 that all donated tissue must be removed from a deceased body within 24 hours, whereafter the body may be claimed for burial or otherwise by family members.
The Act and the regulations are silent on circulatory death, and it is therefore assumed that it is left in the hands of the treating physician to establish death using cardiorespiratory criteria. It seems in the case of cardiac arrest that even fewer routine referrals for organ harvesting take place. Including this way of determining death in a routine referral policy for organ retrieval could have a significant influence on the number of organs available for transplantations. All that is needed is for the treating physician to routinely and timeously refer such a possible death to the transplant co-ordinators. Time is a bigger issue in cardiac arrest than with brain-stem death. In brain-stem death, blood circulation continues via machines, and the organs therefore do not deteriorate, but in cardiac arrest, the blood circulation stops the moment the heart stops beating and the organs start deteriorating immediately, which complicates the transplant process. Other countries and authors have included DCD as a major possibility to increase the availability of transplantable organs.

\section{International deceased-donor organ retrieval}

\section{World Health Organization}

In March 2010, the third World Health Organization (WHO) global consultation on organ donation and transplantation (The Madrid Resolution) called on countries to pursue self-sufficiency in transplantation in compliance with the WHO guiding principles on human cell, tissue and organ transplantation. ${ }^{[7]}$ This included a call to maximise donation by incorporating it in all appropriate end-of-life care programmes. ${ }^{[8]}$

In relation to the guiding principles of the WHO, Dominguez-Gil et al. ${ }^{[9]}$ list 10 changes that could help improve the donor rate:

1. Routine referral: Successful donation programmes have a fundamental reliance on the timely identification, referral and assessment of all possible donors. Patients identified as possible organ donors should be routinely referred to the transplant co-ordinator. The advantage of this system is that assessment of the patient as a potential donor can begin earlier, reducing subsequent delays for both the intensive care unit (ICU) and the donor family. The approach to the donor family can also be planned better.

2. Clinical triggers for donor identification: This should be developed by a panel of experts, and be simple, clearly defined and easy to audit.

3. Accurate donor assessment: All possible donors should be referred regardless of apparent medical contraindications, with decisions about medical suitability being made by the transplant co-ordinator and the transplant teams, not the treating physician.

\section{Systematic brain-death testing.}

5. Goal-directed optimisation of brain-dead donors.

6. Appropriate family approach to discuss the option of organ donation: Only professionals specifically trained should be in charge of the family approach. Organ donation should never be requested until the family has understood and accepted the inevitability of death.

7. Education and training: ICU staff should receive comprehensive training on organ donations.

8. Audit and performance management: Accurate audits of practices are a prerequisite of any attempt to improve donation processes. 
9. Clinical champions for organ donation: The identification of an ICU clinician to arrange organ donations has many benefits. The designated person could raise awareness and provide education.

10. Donation as part of end-of-life care: The primary duty of a physician caring for a patient is to preserve life. However, when brain death has occurred or it has been recognised that further active treatments are no longer in the best interest of the patient, the duties of a doctor shift to palliation and end-of-life care. When this happens, the doctor should immediately see the possibility of benefiting another patient through the process of an organ transplant.

These 10 changes could have an enormous effect on the availability of organs for transplantation. SA could benefit hugely should these changes become national policy, as currently there is no routine referral system and there is a lack of education and training, not only for physicians but also ICU personnel in general. Martesanz ${ }^{[10]}$ argues: '[ $f$ ] or the physician in charge of the potential donor the easiest thing is to find an excuse for not considering the patient as a donor, which will allow him or her to close the case as quickly as possible, thus avoiding a long and complicated procedure.'The authors are of the opinion that this is specifically true in the SA public sector, where the general attitude of physicians is that the living have a higher priority than end-of-life patients due to a lack of resources (e.g. bed availability in ICU). This leads a physician to generally close a case as fast as possible after the confirmed brain or circulatory death of a patient. A required referral policy could slow the physician down for a few moments to save valuable, healthy and life-saving organs. To increase organ availability, SA still follows the 'classic approach', which includes publicity campaigns, a donor registry (which is only for statistical purposes), donor cards and stickers on drivers' licences. This has proved not to be sufficient in supplying the demand. Other countries such as Spain and the UK, and Pennsylvania in the USA have tried the 10 proposals (more or less) and are already making a difference in the numbers reflecting organ transplantations.

\section{Spain}

Spain is the only example of a large country that has seen a continuous increase in deceased organ donation for over 20 years. ${ }^{[1]}$ Spain is also the only country in the world (excluding those who pay living donors, such as Iran) ${ }^{[12]}$ with a progressive decrease in the renal transplant waiting lists. ${ }^{[13]}$ In 2014, 4360 transplants were performed, with a deceased organ donation rate of 36 per one million inhabitants. ${ }^{[14]}$

The Spanish model includes a National Transplant Organisation (ONT) as part of Spain's health ministry, the early referral of possible donors to transplant co-ordinators, a family-based approach and the development of additional training courses aimed at specific groups of professionals. Spain has had a system of 'opting out' since 1979. In an 'opting out' system, every citizen is considered an organ donor unless he or she has, while still alive, indicated that he or she is not willing to be a donor. ${ }^{[12]}$ Despite having this system of organ procurement, relatives are always approached for consent before the organs of the deceased are harvested, and they have the right to a final veto. It is not the system of 'opting out' that has increased the donors in Spain; it is rather having a systematic and organisational approach to the process of deceased donation.
Apart from having a routine referral system, a transplant co-ordinator is appointed at each hospital, and they are usually in-house professionals ${ }^{[11]}$ supported by nurses. Both the physicians and the nurses are totally independent of the transplant teams. 'If you want more donors, you should involve intensive-care specialists in the process of organ donation. If they are not involved, you will not get donors.'[15] Training is essential, as well as the reimbursement of hospitals for their donation and transplant activities. ${ }^{[13]}$ The ONT had, up to 2015 , trained 16000 health workers from top to bottom, so that everyone is aware of the opportunities to gain donors and follow the right protocols to protect organs and tissue.

The Spanish government came to the realisation that a lack of transplantable organs is not the result of a lack of potential donors, but rather a failure to convert potential donors into actual donors. ${ }^{[16]}$

\section{United Kingdom}

The UK has one of the lowest rates of organ donation in Western Europe. In reaction to this, the UK's Department of Health created an Organ Donation Taskforce in 2007 to investigate organ donations. This taskforce reported back to the department in 2008. According to them, there are two factors known to militate against success in increasing donor rates: firstly, physicians' unwillingness to refer patients for a possible organ donation, and secondly, the lack of brain-death testing. ${ }^{[17]}$ The taskforce also recommended that nonheart-beating donors should also be included in the possible pool of available organs, and found that 'the key to success was incorporating donation as a normal part of end-of-life care: there has to be an acceptance by all staff responsible for the care of potential donors that organ donation is a normal part of end-of-life care and that the option of donation must be explored in all suitable circumstances.[18] The referrals should be made regardless of the impression of the clinical staff as to the suitability of the patient for donation. In September 2014, the UK's Department of Health published UK (NHS) Blood and Transplant: Timely Identification and Referral of Potential Organ Donors: A Strategy for Implementation of Best Practice. According to this document, any successful deceased organ donation programme has a fundamental reliance on the identification and referral of all potential donors. Organising safe and effective organ retrieval takes time. It requires detailed assessment of the potential donor, careful evaluation of potential recipients and mobilisation of the relevant retrieval team(s), who might be some distance away. Recipients must be admitted to the transplanting centre before retrieval begins, and delays should be kept to the minimum.

Every hospital should have a written policy for the identification and timely referral of all potential donors. This must be a standard operating procedure.

\section{United States of America}

Due to the increasing success of transplantations, the number of patients waiting for an organ has increased tremendously in the USA, yet the number of organ donors has not kept pace with the need. The shortage of organs poses a public health crisis that need not exist. ${ }^{[19]}$ Federal government accepted that the problem of an inadequate supply of transplantable organs should be addressed at state legislation level. ${ }^{[20]}$

Only the state of Pennsylvania is discussed, as their legal framework resonates with the arguments in this article. Pennsylvania has 
legislated routine referrals, which determine that all patients at or near the time of death, regardless of age or disease, must be referred to a transplant co-ordinator. ${ }^{[2]]}$ The Department of Health monitors compliance via retrospective reviews of medical records, and imposes a fine of up to $\$ 500$ for each instance of hospital noncompliance. ${ }^{[19]}$ The nursing staff are mainly responsible for referrals, and hospital compliance must be recorded in the patient's medical records. The Delaware Valley Transplant Program was developed by an organ procurement organisation to develop a strategy to implement hospital protocols required by law. Intensive training was conducted. Meetings were organised with the practitioners who were most closely involved in possible donations, namely neuroscientists, trauma surgeons, intensivists and critical care nurse managers. The total potential organ donor referrals of ventilator-dependent and neurologically impaired patients dramatically increased from 528 in 1994 (prior to the legislative change) to 824 in 1996 (post the implementation of the law) - an increase of $56 \%$. Referrals of braindead patients increased from 342 to 427 (a 25\% increase) and the number of organ donations increased from 175 to 217 (24\%) over the same period. '[R]outine referral law with aggressive implementation effectively changed staff behaviour and procedures.'[22]

\section{SA - the way forward}

There are a number of challenges faced by SA concerning organ retrieval. If the success of Spain is taken into consideration, it seems as if it is not the system of 'opting in' that is the problem. Spain, even with an 'opting out' system, still asks the relatives of the deceased for consent before organs are removed. The system of organ procurement is therefore not the key to increase the donor pool. It seems as if the ten changes proposed by Dominguez-Gil et al., ${ }^{[8,9]}$ in tandem with the vision of the WHO, are a better way of addressing organ retrieval.

A major shortcoming in SA is that there is no national organ procurement organisation. ${ }^{[12]}$ It is argued that such an organisation would be hugely beneficial. An SA National Organ Procurement Organisation (SANOPO), ${ }^{[23]}$ functioning as a not-for-profit company, could assist with promotion, education and the organisational structures required to increase the numbers of referred donors. The SANOPO should function like the SA National Blood Service, by charging a fixed service fee per transplant to cover the significant costs of donor care, organ procurement and the transport of organs to the transplant facility. Medical schemes, the government or individuals should pay such fees as they pay for blood or blood products. An improved contact process such as a national call centre should ensure that the expected increase of referral is managed efficiently. Transplant co-ordinators should also be affiliated to the SANOPO to ensure an efficient service and to ensure their independent practice in the management of potential donors. In such a system, hospitals, whether private or public, will know whom to contact in the case of a potential donor.

In addition to an organ procurement agency, there should be a drive for massive educational and awareness programmes to be instituted amongst medical students ${ }^{[23]}$ as well as practising physicians and nursing staff. Government should also implement a routine legislated referral policy to be followed by all hospitals, and there should be a fine for non-compliance, as is the case in Pennsylvania.

$\mathrm{SA}$ is a member of the WHO and a signatory to the Declaration of Istanbul. There is therefore a governmental duty to develop policies and procedure to maximise the number of organs available for transplantation. Unfortunately, the current position is not in conformity with these ideals. Referrals happen on an ad hoc basis, and it depends on the staff of a hospital whether a transplant co-ordinator is contacted or not. Many potential donations go to waste because no formal policy is in place.

\section{Conclusion}

This article has sought to examine the current practices followed by Spain, the UK and Pennsylvania to improve their current organ shortage situation to guide SA in their attempt to adopt similar practices. SA can learn a number of lessons from the countries discussed above. If one looks at the current organ donation practices followed by Spain, it is evident that an opt-out procurement system will not make a significant difference to the current acute shortage. However, Spain has experienced great success with their routine referral process system. The UK serves as a perfect example to illustrate that organ shortage numbers can be improved by incorporating potential organ donation discussions as part of general end-of-life care. Once the process of routine referral has been adopted within the SA sphere, it will even be possible to follow in the steps of Pennsylvania, which legislated routine referral and even added a fine for non-compliance. It is clear that the current altruistic system of organ procurement in SA is not successful, as the number of organs available for transplantation purposes remains stagnant. The best basic step to start with at this point would be for the Department of Health to implement a routine referral policy document compelling physicians to refer every death to be evaluated for the possibility of organ retrieval. This would create a strong incentive to create a SANOPO to efficiently respond to the expected increase in referrals. SANOPO would ensure the promotion and application of the other principles suggested by Dominguez-Gil et al. ${ }^{[8,9]}$ to ensure an efficient process from referral to procurement to transplant.

Acknowledgements. The authors would like to thank Dr Errol Gotthlich (paediatric nephrologist) for his contributions with regard to this publication. Furthermore, the authors would like to acknowledge the fact that he conceived the original idea of the concept of SANOPO.

1. Rudge C, Matesanz R, Delmonico FL, Chapman J. International practices of organ donation. Br J Anaesth 2012;108(1):i48. http://dx.doi.org/10.1093/bja/aer399

2. The Organ Donor Foundation. Transplant Statistics. www.odf.org.za (accessed 26 August 2016).

3. South African Government. Statistics South Africa on Mortality and Causes of Death 2013. 2014 www.gov.za/mortality-and-causes-death-2013 (accessed 30 August 2016).

4. Citerio G, Cypel M, Dobb GJ, Dominuez-Gil B, et al. Organ donation in adults: a critical care perspective. Intensive Care Med 2016;42(3):306. http://dx.doi. org/10.1007/s00134-015-4191-5

5. Citerio G, Cypel M, Dobb GJ, Dominuez-Gil B, et al. Organ donation in adults: a critical care perspective. Intensive Care Med 2016;42(3):308. http://dx.doi. org/10.1007/s00134-015-4191-5

6. Citerio G, Cypel M, Dobb GJ, Dominuez-Gil B, et al. Organ donation in adults: a critical care perspective. Intensive Care Med 2016;42(3):309. http://dx.doi. org/10.1007/s00134-015-4191-5

7. World Health Organization. Guiding Principles for Transplantation. 2016 http:// www.who.int/transplantation/Guiding_PrinciplesTransplantation_WHA63.22en. pc (accessed 30 August 2016).

8. Dominguez-Gil, Murphy P, Procaccio F. Ten changes that could improve organ donation in the intensive care unit. Intensive Care Med 2016;42(2):264. http:// dx.doi.org/10.1007/s00134-015-3833-y

9. Dominguez-Gil, Murphy P, Procaccio F. Ten changes that could improve organ donation in the intensive care unit. Intensive Care Med 2016;42(2):265. http:// dx.doi.org/10.1007/s00134-015-3833-y 
10. Martesanz R. A decade of continuous improvement in cadaveric organ donation: The Spanish model. Nefrologia 2002;15(1):22-28.

11. Soyama $A$ and Eguchi $S$. The current status and future perspectives of organ donation in Japan: learning from the systems in other countries. Surg Today 2016;46(4):388. http://doi.org/10.1007/s00595-015-1211-6

12. Venter $B$, Slabbert $M$. Rewarding a living kidney donor: $A$ comparison between South Africa, Singapore and Iran. Obiter: 2013;34(2):185.

13. Martesanz R. A decade of continuous improvement in cadaveric organ donation: the Spanish model Nefrologia 2002;15(1):61.

14. Badcock J. How Spain became the world leader in organ donation. 2015. http://europe.newsweek.com/spain-has-become-world-leader-organdonations-305841 (accessed 30 August 2016).

15. Martesanz R. A decade of continuous improvement in cadaveric organ donation: the Spanish model Nefrologia 2002;15(1):65.

16. Miranda B, Fernandez L, de Felipe C, Naya M, Gonzalez-Posada JM, Matesanz R. Organ donation in Spain. Nephrol Dial Transplant 1999;14(3):21.

17. Murphy F, Cochran D and Thornton S. Impact of a bereavement and donation service incorporating mandatory 'required referral' on organ donation rates: A model for the implementation of the Organ Donation Taskforce's recommendations. Anaesthesia 2009;64(8):822. https://doi.org/10.1111/j.13652044.2009.05932.x
18. Murphy F, Cochran D and Thornton S. Impact of a bereavement and donation service incorporating mandatory 'required referral' on organ donation rates: a model for the implementation of the Organ Donation Taskforce's recommendations. Anaesthesia 2009;64(8):823. https://doi.org/10.1111/j.13652044.2009.05932.x

19. Robertson VM, George GD, Gedich PS, Haz RD, Kochik RA and Nathan HM. Concentrated professional education to implement routine referral legislation increases organ donation. Transplantation Proceedings 1998;30:214. https://doi. org/10.1016/S0041-1345(97)01241-4

20. Pollard S. The impact of state legislation on organ donation - results of a US pilot scheme. Nephrol Dial Transplant 1997;12(12):2511. https://doi.org/10.1093/ ndt $/ 12.12 .2510$

21. Pennsylvania. Act 102 of 1994. Robertson VM, George GD, Gedich PS, Haz RD, Kochik RA and Nathan HM. Concentrated professional education to implement routine referral legislation increases organ donation. Transplant Proc 1998:(30):216. https://doi.org/10.1016/S0041-1345(97)01241-4

22. Sobnach S, Borkhum M, Millar AJW et al. Attitudes and Beliefs of South Africa medical students toward organ transplantation. Clin Transplant 2012;26(2): 192. https://doi.org/10.1111/j.1399-0012.2011.01449.x 